A RTIGOS TrRADUZIDOS/

TrRANSLATED A RTICLES 


\title{
A TRADUÇÃO ENTRE AS CULTURAS ${ }^{1}$
}

\author{
Marc Crépon* \\ École Normale Superiéure em Paris
}

Tradução de:

Henrique de Oliveira Lee**

Vinícius Pereira Carvalho***

Arildo Leal de Paula Junior***

Universidade Federal de Mato Grosso

${ }^{1}$ Artigo originalmente intitulado « La traduction entre les cultures » publicado na Revue Germanique Internationale, vol.21, 2004, p.71-82.

* Doutor em Filosofia e tradutor, Diretor de Pesquisa no CNRS (Centre Nationale de Recherche Scientifique), chefe do departamento de Filosofia da École Normale Superiéure em Paris

${ }^{* *}$ Henrique de Oliveira Lee, professor do Programa de Pós-Graduação em Estudos da Linguagem na Universidade Federal de Mato Grosso, possui doutorado em Literatura Comparada pela Universidade Federal de Minas Gerais, coordenador do Programa de Extensão "Estudos da Alteridade e Tradução", Cuiabá. Mato Grosso, Brasil. E-mail: holiveiralee@gmail.com.

*** Vinícius Carvalho Pereira, professor do Programa de Pós-Graduação em Estudos da Linguagem na Universidade Federal de Mato Grosso, possui doutorado em Ciência da Literatura pela Universidade Federal do Rio de Janeiro. Universidade Federal de Mato Grosso. E-mail: viniciuscarpe@gmail.com

**** Arildo Leal de Paula Junior, aluno do curso de graduação em Letras da UFMT, extensionista do Programa de Extensão "Estudos da Alteridade e Tradução”. Universidade Federal de Mato Grosso. E-mail: arildo@mail.ru 
Resumo: O presente artigo interroga sobre a pertinência de uma compreensão da interculturalidade em termos de tradução entre as culturas. Esta hipótese é estudada em duas direções: 1) o horizonte cosmopolita cuja ideia de tradução implica; 2) a crítica das premissas de origem única e homogeneidade das culturas que tal hipótese torna possível.

Palavras-chave: Tradução. Interculturalidade. Cosmopolitismo.

\title{
TRANSLATION BETWEEN CULTURES
}

\begin{abstract}
This article will question the pertinence of understanding interculturality in terms of translation between cultures. I shall study this hypothesis in two ways : $1 /$ the cosmopolitan horizon, which the idea of translation may implicate ; 2 / the critique of the premises of unique origin and homogeneity of cultures which this hypothesis makes possible.
\end{abstract}

Keywords: Translation. Interculturality. Cosmopolitism.

A questão que formularei é a seguinte: Pode-se pensar a relação entre as culturas segundo o modelo de uma tradução? É legítimo estender isso que podemos experimentar da relação entre as línguas (a que ocorre entre elas e em cada uma delas na tradução) à interculturalidade? Na realidade, trata-se de duas questões, pois esta extensão pode ser pensada de duas maneiras.

\section{A tradução como horizonte cosmopolita}

A primeira é programática e teleológica. Ela consiste em dizer que as culturas são predestinadas a se traduzir umas pelas outras, que não têm outro devir senão essa relação comum que enriquece cada uma com o que recebe das outras - múltiplas passagens, trocas, transferências que dão a cada uma sua identidade, ao mesmo tempo em que ratificam suas características comuns. A tradução entre as culturas, então, não é percebida como um fenômeno pontual e episódico (algo que aconteceria às vezes a esta ou aquela). Ela é aquilo que virá e deve vir - a prometida e progressiva superação da sua compartimentação ou de sua redobra sobre si próprias. 
Pensar a relação entre as culturas como tradução é anunciar que será impossível doravante falar das diferentes culturas como entidades homogêneas, desenvolvidas a partir de um fundo próprio, pois, pelo viés da tradução, elas não poderão permanecer idênticas a si mesmas. Elas progressivamente serão, cada uma de maneira singular, um espelho das demais. Tomada sob tal perspectiva, a extensão do conceito de tradução consiste em pensar a relação entre as culturas em um horizonte cosmopolita. A interculturalidade aí desenha os contornos de uma nova utopia - um mundo no qual as fronteiras culturais, as barreiras que as culturas erguem entre os indivíduos, serão abolidas.

Dessa dimensão teleológica, até mesmo profética, dessa esperança cosmopolita, algumas das principais teorias da tradição linguística oferecem o modelo - a começar pelo que Benjamin propõe em "A tarefa do tradutor" 2 . O que diz ele da tradução que pudesse esclarecer esse horizonte? Que ela é, no tempo de sua execução, o sinal que remete a pluralidade das línguas a uma língua pura ${ }^{3}$, comum a todas. Da obra literária, Benjamin reconhece a condição singular de valer como um chamado em direção a essa linguagem. A obra literária, enquanto tal, reclama seu transborda-

2 N.A. Mas poderíamos ainda acrescentar as reflexões de Rosenzweig sobre a tradução e principalmente sua tradução da Bíblia para o alemão, com Buber (cf. "Traduction et rédemption, la question du nationalisme dans l'œuvre de Rosenzweig”, in Marc Crépon, Le malin génie des langues, Paris, Vrin, 2000, p. 141-155), ou, mais próximo de nós, o trabalho de Jacques Derrida sobre esta questão.

${ }^{3}$ N.T. Reine Sprache é uma expressão do célebre texto de Walter Benjamin, A tarefa do tradutor [Die Aufgabe des Übersetzers], que possui um estatuto conceitual. Traduzido tanto por "língua pura" como por "linguagem pura" a expressão designa uma relação de afinidade supra-histórica entre as línguas, que apareceria só e unicamente no texto traduzido e que em última instância apontaria para um elemento comum a todas as línguas. Esse elemento resultaria do direcionamento de todas as línguas a algo que lhes seria comum e que não poderia ser apreendido por cada uma delas isoladamente, mas que surgiria como resultado de suas "intenções reciprocamente complementares" [ihrer einander ergänzenden Intentionen]. $\mathrm{O}$ autor verteu a expressão alemã para o francês como langage pur. 
mento em uma língua dada. Porque ela não se reduz a sua comunicação, ela tende a um outro horizonte: aquele da harmonia das línguas. Traduzir, para Benjamin, é colocar à prova até que ponto as línguas entretêm uma relação íntima - é experimentar o fato de que são aparentadas. A tradução as faz convergir ao infinito.

De tal postulado, presente aqui de modo sucinto ${ }^{4}$ várias coisas podem ser mantidas. Primeiro que a tradução é portadora de uma promessa que, se poderia quase dizer escatológica. Ela remete aos "fins da humanidade". Mais além do parentesco que ela faz pressentir, a tradução se apresenta como um trabalho, uma obra que conduz os homens em uma certa direção. Traduzir, mas também confrontar-se com traduções (ler as traduções), é ter uma experiência de sua língua que torna impossível fechar-se em uma cultura determinada, é desvincular a experiência e a prática da língua - mas também o prazer extraído da(s) língua(s) - de todo sentimento de pertencimento. Isso que chega à língua, isso que me chega pela língua me vem de alhures. Basta dizer que a tradução opera uma verdadeira desapropriação da minha (nossa) língua - ela a deporta em direção a uma comunidade que não é mais somente aquela dos seus co-locutores. Ela me aproxima daqueles que falam outras línguas (as línguas traduzidas), da mesma forma que o que se traduz da língua deles na minha língua os aproxima de mim e faz com que essa língua não seja mais de modo algum, ou pelo menos não mais exclusivamente, a minha. $\mathrm{O}$ que se turva com a tradução é o mapa do meu e do seu. É também todo o sonho de uma apropriação (de um domínio e de uma posse da sua língua, como "língua materna”). Não posso ser senhor da minha língua, não posso jamais possuí-la, a partir do momento em que não sou senhor disso que, pelo viés da tradução, pode, a cada instante, ocorrer-lhe.

Mas também a teoria benjaminiana da tradução nos ensina que nenhuma língua é autossuficiente. Ela nos diz mesmo que nunca

${ }^{4}$ N.A. Cf. "La magie du langage, Benjamin et les surréalistes”, in Marc Crépon, Les Promesses du langage, Paris, Vrin, 2001, p 101-131. 
as línguas o foram. Ela remete para um "sempre", o "sempre" da tradução, cujo primeiro efeito é tornar caduco todo recurso a uma hipotética origem. Sempre as línguas viveram da tradução e pela tradução. Esta não veio a elas a posteriori - uma vez que elas estivessem já constituídas (como uma catástrofe ou como enriquecimento). A tradução é antes a lei do devir das línguas. O que faz a grandeza de uma língua (supondo que tal expressão ainda tenha sentido) não é sua antiguidade nem sua origem, não é que ela seja aparentada a tal ou tal língua que a faria objeto de uma valorização por si mesma problemática (o grego, o latim, o sânscrito), é que ela permaneceu (e ainda permanece) disponível à tradução - é que, graças a ela, (se) tem tradução. Toda língua é, então, tributária disso que se traduz nela e a partir dela, para as outras, pois é somente então que ela acena para essa língua pura ainda inacessível (e de todo modo hipotética) que não é nenhuma outra, senão uma língua completamente desapropriada, uma língua que, por não ser propriedade de ninguém, poderia ser comum a todos - uma língua prometida.

Esse modelo profético tem um sentido, quando não se fala mais de tradução entre as línguas, mas de tradução entre as culturas. Isso suporia que se fizesse dessa tradução "um”, senão "o" fim do homem. O horizonte cosmopolita da diversidade de culturas seria sua tradução respectiva umas pelas outras. Mas, desde já, várias questões se colocam, que são de duas ordens.

1. Desde que se sigam as reflexões de Benjamin, que se busca transpor da diversidade das línguas à das culturas, confronta-se a seguinte dificuldade: qual harmonia e qual unidade se mostram nessa tradução? Qual é o sentido dessa tarefa infinita e inacabável que seria a tradução das culturas, que promessa se encontra aí investida? Qual é o equivalente dessa "língua pura" que postula Benjamin? Somos, uma vez mais, reconduzidos ao postulado da unidade e da identidade da natureza humana? Se tal for o caso, não poderia mais se tratar de uma ideia transcendente, mas somente de uma unidade imanente: a unidade de um fazer. Pela "tradução intercultural" se faria a humanidade. E o que assim se faria não poderia ser em nenhum caso a redução das diferenças. Ao contrário, 
só haveria unidade por e na diversidade dos modos de tradução. As culturas não tiveram (e nunca têm) a mesma maneira de traduzir e de se traduzir. Elas não estiveram em contato da mesma maneira. Não se pode negar que, em toda época histórica, houve "culturas dominantes" ou "radiantes" (sem que essa dominação ou radiação implique aqui qualquer aumento de valor ou uma hipotética superioridade espiritual) e as "culturas dominadas". Houve as culturas que, por razões históricas, logo se prestaram a serem "traduzidas" - que se encontravam na posição de impor às demais a necessidade ${ }^{5}$ de as "traduzir". A outras, ao contrário, era dificilmente (quiçá, nunca) reconhecido que tivessem o quer que seja para traduzir (e que entretanto se traduzem). E no entanto, nessa pluralidade de modos de tradução da diversidade, permanece um denominador comum: a tradução ela mesma. Para dizer de outra maneira, a unidade que se encontraria revelada na tradução e pela tradução não seria nada senão o próprio traduzir. Haveria de certo modo um "isso se traduz" ou "isso traduz" comum a todas as culturas. $\mathrm{Ou}$ ainda um "em toda a cultura há tradução".

2. A segunda ordem de questões nos reconduz a nossa indagação inicial e submete a primeira às suas condições. Esta seria: É legitimo falar de tradução entre culturas? Pode-se aplicar sem reservas o conceito de tradução a uma passagem, para uma relação diferente daquelas que ocorrem nas línguas e entre as línguas. Tradicionalmente, fala-se sobretudo de empréstimos, de importações e (ou) de exportações de "conteúdos culturais". Ressalta-se a maneira como costumes, práticas culinárias e indumentárias, tradições passam de um "ar cultural" a outro, tornando-se parte integrante (não sem resistência, às vezes) do "ar cultural" que os recebe. Pensa-se, enfim, a título de mestiçagem, a mistura ou a coexistência desses conteúdos que se diz serem de origens diferentes (religiões, modos de se vestir, modos de se alimentar, ritos etc.). De tal ponto de vista, é preciso, antes, sublinhar os seus limites. Ele preserva

${ }^{5}$ N.A. Ver adiante como a teoria antropológica das "ramificações” (J.-L. Amselle) permite esclarecer essa necessidade. 
o dogma de culturas homogêneas originais (idênticas a si mesmas) que devem aprender a coexistir ou que se misturam umas as outras, em um segundo tempo somente.

É esse segundo tempo que se faz problemático. E é para resolver esse problema que o conceito de tradução deve estar afinado. Esse conceito, com efeito, supõe primeiramente mais que uma transferência ou uma simples importação. Não há tradução sem transformação. Traduzir é passar de um significante a outro - preservando, tanto quanto possível, mas jamais totalmente, - o significado. Se a tradução entre as culturas tivesse que se mostrar o modelo mais pertinente para se pensar a interculturalidade, ela suporia uma passagem dessa ordem. Ela implicaria a existência de significados culturais que, de uma cultura a outra, mudam de significante - ou ainda significados cuja passagem exige a invenção de um outro significante (uma invenção que se tornaria então o motor privilegiado do devir das culturas). A ideia de atribuir à tradução entre culturas uma dimensão escatológica comparável àquela que Benjamin atribuía a tradução entre as línguas exige, portanto, que se tenha previamente respondido a questão: É dessa forma (à custa de tal mudança de significante) que as culturas se traduzem - ou mesmo sempre foram traduzidas?

Mas o conceito de tradução deve sugerir mais ainda, se queremos acabar com essa ideia de um segundo tempo - isto é, sair do preconceito durável, segundo o qual aquilo que se passaria entre as culturas (isso que lhes ocorreria) viria sempre posteriormente, em um segundo tempo. Enquanto esse preconceito perdura, de fato, a história das culturas reconduz a uma anterioridade da identidade em relação a isso que lhe ocorre e, portanto, aos mitos conjuntos da origem e da homogeneidade. Em um texto célebre, Jakobson distingue três tipos de tradução:

A tradução intralingual ou reformulação (rewording) consiste na interpretação dos signos linguísticos por meio de outros signos da mesma língua. A tradução interlingual 
ou tradução propriamente dita consiste na interpretação de signos linguísticos por meio de outra língua. A tradução intersemiótica ou transmutação consiste na interpretação dos signos linguísticos por meio de sistemas de signos não linguísticos. ${ }^{6}$

Se nos atemos a tal classificação para pensar a interculturalidade, o dogma do segundo tempo é mantido intacto. Teríamos três tipos de traduções interculturais. Aquela que transcreve no mesmo sistema de signos um fenômeno cultural (por exemplo, as diferentes versões de uma mesma história no cinema), aquela que transcreve esse fenômeno de uma cultura para outra (como a adaptação americana de um filme europeu), aquela que por fim traduz um fenômeno cultural dado para outro sistema de signos (a adaptação cinematográfica de um romance, até mesmo de uma canção ou de um conjunto de canções) ${ }^{7}$. Em todas essas hipóteses, a tradução é sempre segunda em relação a uma identidade primeira. É portanto um quarto modelo de tradução intralinguística que se deve implicar: uma tradução - anterior à tradução, uma tradução que poderíamos quase dizer originária, se quisermos deslocar (perverter, talvez) a noção de origem. Tratar-se-ia então de pensar a identidade cultural sob o modelo de uma identidade linguística que não se constituiria senão por e na tradução.

Isso feito, é necessário retornar mais uma vez da dimensão futura à dimensão do passado - mostrar que efetivamente toda a cultura é, em sua identidade, de modo constitutivo, o resultado de uma tradução, que não é nem exploração nem desenvolvimento de um fundo próprio que teria o estatuto de um arquipatrimônio.

\footnotetext{
${ }^{6}$ N.A Jakobson, Essais de linguistique générale, t. I, Paris, Éd. de Minuit, 1963, p. 79.

${ }^{7}$ N.A Ver, por exemplo, o filme de Alain Resnais On connaît la chanson, que retrata concomitantemente as canções populares e sua tradução dentro da narrativa que as entrelaça. N.T. No Brasil o filme de Resnais é encontrado sob o título Amores Parisienses.
} 
Para elucidar, como se tentou fazer, a questão da harmonia (reduzindo-a ao fato bruto da tradução como um denominador comum), é preciso portanto passar da dimensão teleológica e mesmo utópica desse pensamento das relações interculturais à sua dimensão crítica

\section{A Tradução no horizonte da crítica}

No começo dessa reflexão, foi feita a suposição de que existiam duas maneiras de pensar a interculturalidade sob o modo de uma tradução. A promessa escatológica era a primeira. A crítica é a segunda. Elas não são, evidentemente, completamente dissociáveis uma da outra.

Sua articulação corresponde justamente a isso que sempre foi a essência da utopia - a saber, a conjunção de um discurso crítico e de um programa que seria sempre mais que um programa e até mesmo mais que uma profecia: uma promessa. Lembra-se, com efeito, que a maioria das descrições proféticas de uma cidade utópica, a começar por $A$ Utopia de Thomas More, se abria para uma crítica da cidade existente, para o recenseamento de todos os males que a assolam antes de projetar um programa de reformas que prometesse solucioná-los em um futuro indeterminado.

Em que consiste aqui a crítica? Qual é a lista de males que ela revela? Poderíamos nos contentar em enumerar as atrocidades (as infelicidades e as misérias) que podem ser colocadas na conta de uma concepção homogeneizante das culturas - narrar os conflitos que, ontem e hoje ainda, tiveram e sempre têm por razão uma concepção de identidade cultural que é também uma negação da tradução. Isso significa que se estivéssemos habituados a pensar a relação entre as culturas em termos de tradução mais do que em termos de concorrência - se tivéssemos compreendido que a tradução não é um episódio aleatório do devir das culturas, mas a condição mesma da vida e da "identidade" delas - teríamos evitado esses fantasmas de alteração e desaparecimento (da usurpação e da 
confusão) que deram aos conflitos identitários um curso tão mortal. Mas, sem dúvida, isso não é suficiente.

A crítica deveria levar mais além. Ela precisa desconstruir a noção mesma de identidade cultural (principalmente, com tudo que ela pode comportar de fantasmas da origem, da unidade, da integridade ou da pureza, etc.) - desconstruir, portanto, esta maneira de compreender, analisar e descrever as identidades culturais como identidades homogêneas, unas e idênticas a elas mesmas, essa maneira também de narrar sua história, a de sua origem, formação e desenvolvimento segundo o esquema de uma unidade. Com a crítica, a questão se encontra então deslocada. Ela não mais concerne ao futuro das culturas, no que elas seriam destinadas a se traduzir umas nas outras - a interculturalidade como horizonte cosmopolita. Ela se interessa pela história inacabada da formação das culturas. Ela tem por objeto colocar em evidência a tradução em si mesma como constituição originária de qualquer cultura. Ela visa mostrar que ao narrar a história constitutiva das culturas, sem ceder ao fantasma de uma origem unidentitária, encontra-se sempre, no começo, tradução. A tradução não vem posteriormente, como supõe toda teoria da mestiçagem. Ela está ali desde sempre.

Mas como se pode mostrar que, de encontro a toda uma tradição de reflexão sobre as identidades culturais ${ }^{8}$, as culturas não são entidades estanques opostas e expostas umas às outras, às quais o desafio de alteridade chegaria um dia como ameaça de uma catástrofe (como uma infelicidade ou uma violência a sua integridade)? Como se pode mostrar que elas são, desde o começo, traduzidas umas pelas outras - que o acontecimento da tradução lhes é então consubstancial? Contra o fantasma de culturas homogêneas - que se deveria proteger ou promover -, a ideia de uma constituição originalmente heterogênea das culturas não deve permanecer uma hipótese teórica e se expor à reprovação de ser mera especulação.

8 N.A Tradição que se encontra ainda nas teorias contemporâneas do multiculturalismo, como as de Charles Taylor e de Will Kymlicka. 
Daí a necessidade de interrogar o trabalho dos antropólogos. É à antropologia atual que é preciso indagar se é verdade que (na visão das pesquisas, cujo método e orientações demandam ser precisadas $^{9}$ e interrogadas) a identidade de cada cultura depende da maneira como cada uma teve, por razões necessariamente diversas - razões, em todo caso, que não remetem em nenhum caso à qualidade singular de um espírito ou de um caráter -, de traduzir ou de não traduzir; se é verdade que essas identidades dependem da extensão daquilo que elas oferecem e ofereceram à tradução, daquilo que elas aceitaram e recusaram, conheceram ou ignoraram.

Voltar-se para a antropologia é também, em um registro mais político (do qual não pode ser feita uma abstração aqui), uma maneira inédita de responder às reivindicações identitárias, de duas maneiras. Poucas disciplinas, antes de tudo, terão experimentado a esse ponto a necessidade de fazer um retorno a si mesmas - de se interrogar sobre sua participação em uma das maiores catástrofes dos dois últimos séculos (o imperialismo colonial) e de recolocar em questão, nessa perspectiva, a pertinência de suas representações e o uso de seus conceitos - a começar por esse de "identidade cultural". Dos antropólogos, pode-se esperar, portanto, que eles tenham já feito uma parte do trabalho por conta própria, que eles já tenham se interrogado, por exemplo, sobre a relação que pode ter existido entre a imposição do registro de uma colônia, a circunscrição administrativa de um território, a identificação de um povo e a definição de um caráter. Eles sabem - mais ainda - que as culturas não são homogêneas; que elas não procedem da exploração infinita de um fundo próprio (ligado a um terreno determinado ou a qualquer outra forma de propriedade); que, durante muito tempo, foi a um ou outro desses paradigmas que eles relacionaram as culturas.

Mas, sobretudo, o recurso à Antropologia se demonstra indispensável, se é verdadeiro que não são impermeáveis os limites entre as definições ou as descrições identitárias de uma cultura dada e os discursos que reivindicam essa identidade e seu reconhecimento,

${ }^{9}$ N.A. A questão do território do antropólogo se revela decisiva aqui. 
que recusam uma teoria do próprio e da propriedade ao mesmo tempo em que formulam o requisito de uma apropriação e lamentam uma perda de identidade ou advertem para uma ameaça de expropriação. De encontro a esses discursos políticos, ela somente está em condições de trazer a prova empírica de que a cultura não se identifica com um feixe de propriedades, com um conjunto das coisas que nos pertenceriam (a língua, os costumes), que não seriam jamais suficientemente apropriadas e que deveríamos temer perder - a língua que não seria mais apropriada (impura, contaminada por palavras estrangeiras, etc.), as tradições cuja perda despojaria "os detentores", "os representantes" ou "os portadores de direito da comunidade" (quem são eles justamente? Que comunidade hipotética eles formam?), os que falam e agem em nome da cultura (em nome do que eles creem deter exclusivamente: suas tradições, precisamente).

Pensar a interculturalidade como tradução consiste, portanto, em se dar os meios de não deixar intacta nenhuma dessas apropriações - em mostrar que o que cada cultura imagina ter de próprio (do qual ela faz um traço característico essencial) é certamente o efeito de uma tradução, até mesmo de uma sucessão de traduções - de tal maneira que será quase impossível separar o original do traduzido. Trata-se de atacar incansavelmente todo discurso que perseveraria na busca de um conteúdo cultural autêntico (qualquer coisa que pertenceria exclusivamente ${ }^{10}$ a uma cultura). É somente à custa de uma

10 N.A Eu me perguntava, ao escrever essas linhas, como deixar lhes dar contornos menos abstratos, que ilustração propor que não fosse uma vez mais a desconstrução de um determinado discurso filosófico sobre a ou as cultura(s), quando meus filhos chegaram da escola. Eles haviam participado, na escola primária em que estudavam, da "semana do gosto" e lhes haviam feito provar diversos temperos, questionando-se se eles conheciam os pratos. A narrativa deles sugeriu-me algumas reflexões. Primeiro, poderíamos dizer que essa semana do gosto, que não privilegia a abordagem dietética e nutritiva dos alimentos, mas seu gosto - não é estranha a uma certa representação da "cultura frances", à ideia, em todo caso, de que essa cultura comporta como um dos elementos constitutivos um certo conhecimento culinário que invoca, em contrapartida, uma "educação do gosto". Ademais, essa semana se justifica por uma deploração comparável 
tal desapropriação que a interculturalidade pode ser legitimamente pensada como tradução e alçar um horizonte cosmopolita.

O que diz hoje a antropologia não somente das culturas atuais, mas também do seu passado ${ }^{11}$ (uma vez que nos é preciso ainda e sempre retornar sobre esta história que terá sido comumente mítica) - o que ela diz que nos possa permitir pensar a relação que as culturas mantêm umas com as outras segundo o modelo de uma tradução constitutiva? A crer nos trabalhos de Jean-Loup Amselle, a disciplina está exposta a dois obstáculos. O primeiro é subscrever à tese segundo a qual, efetivamente, não haveria mais hoje culturas

àquelas que se analisava um pouco mais acima. $\mathrm{O}$ gosto se perde, as crianças não sabem mais reconhecer os sabores. Mais um pouco, ele não serão mesmo capazes de apreciar como se deve esta cozinha que faz, no entanto, parte da sua cultura; eles se encontrarão de alguma maneira despossuídos, em proveito de uma alimentação padronizada. Mas a essas duas observações , é preciso, em seguida, acrescentar uma terceira. $\mathrm{O}$ que aprenderam a reconhecer essas crianças cujo gosto devia ser educado? Frutas, entre cujos nomes figuravam os abacaxis. Temperos que, há alguns séculos, eram totalmente desconhecidos na Europa. Frutas, temperos que doravante entram na composição de numerosos pratos que identificamos como "culinária francesa". Disse a mim mesmo, então, que havia aí uma história (que certamente já foi escrita) que implicava toda uma série de passagens: a viagem dos temperos , suas primeiras adaptações, sua associação com outros produtos, carnes, legumes, peixes que talvez não se cozinhassem lá onde foram cultivados. Tudo isso para dizer que, para a reflexão, a "culinária francesa", florão da "cultura", era finalmente um assunto bastante complicado que necessitaria de muitas mediações, apropriações não somente de produtos, mas também de saberes desenvolvidos alhures. E que ao fazer a história dessas apropriações-traduções sucessivas, ela se revelou tributária de outras culturas (nos dois sentidos do termo), de outras tradições culinárias, de modo que, finalmente, seria bastante difícil fazer desta culinária a "própria" de uma cultura determinada, ainda menos a expressão de um gênio culinário próprio de uma localidade ou uma série de localidades.

${ }^{11}$ N.A Em Au cœur de l'ethnie (Paris, La Découverte, 1985), Jean-Loup Amselle relembra quanto foi grande a hostilidade que, durante muito tempo, a antropologia manifestou contra toda abordagem histórica ou historicista das culturas. Essa abordagem histórica é porém necessária, se queremos proceder à desconstrução do mito de identidades culturais homogêneas e idênticas a si mesmas. A tarefa da história, na antropologia, é romper com o molde da homogeneidade e de identidade, colocando a heterogeneidade no coração da origem. 
homogêneas - mas somente um mundo homogêneo. Ou sobretudo, as culturas pesariam muito pouco diante da globalização e da homogeneização de um mundo que já estaria decidido quanto ao destino delas - destinando-as senão a um desaparecimento certo, ao menos a uma "folclorização" cada vez mais exótica. Das culturas, não restaria, a termo, mais do que seu folclore. O segundo consiste em crer que esse novo estado de fato põe um fim a um passado no qual as culturas estavam claramente diferenciadas e compartimentadas. Para dizer em outros termos, teria havido um tempo no qual a apropriação era natural e imediata (cada um tinha uma cultura, a cultura própria para sua comunidade - uma cultura distinta de todas as outras que o incluía nessa comunidade e seria suficiente para diferenciá-lo de todos aqueles que não faziam parte dela) e um tempo em que elas teriam começado a se misturar umas às outras, sob risco de uma confusão maior, até mesmo de se ferir (para resistir a essa mistura). Choque de culturas ou "creolização" 12 do mundo, para retomar os termos de Édouard Glissant, nos dois casos se encontra postulada a existência original de culturas diferenciadas. Ambos são dominados por uma remissão a uma apropriação original.

${ }^{12}$ N.A Ver a critica que J.-L. Amselle faz da teoria de uma "creolização do mundo", em seu último livro Branchements, anthopologie de l'universitalité des cultures, Paris, Flammarion, 2001, p. 17 sq. :"L'idée de créolisation correspond à une conception polygéniste du peuplement humain, dans laquelle les differénces espèces feraient l'objet d'un travail permanent de croisement et d'hybridation. Ce boutage culturel du monde représente ainsi l'avatar ultime de la pensée biologicoculturelle, telle qu'elle s'est pleinement développée dans l'antropologie culturelle américaine. C'est en partant du postulat de l'existence d'entités culturelles discrètes nommées "cultures" que l'on aboutit à une conception d'un monde postcolonial ou postérieur à la guerre froide vu comme être hybrides" [A ideia de creolização corresponde a uma concepção poligenista da humanidade, na qual as diferentes espécies seriam objeto de um trabalho permanente de cruzamento e hibridação. Essa irrupção cultural do mundo representa, assim, o avatar último do pensamento biológico-cultural, tal como é plenamente desenvolvido na antropologia cultural americana. É partindo do postulado da existência de entidades culturais discretamente denominadas "culturas" que se chega a uma concepção de um mundo pós-colonial ou posterior à guerra-fria de seres híbridos]. (op. cit., p. 21-22). 
Se a antropologia é particularmente bem aparelhada para medir tais riscos, é que desde muito tempo, ela foi dominada por tal postulado. Este (que pressupõe, desde a origem, sociedades fechadas) se impunha com tanta evidência que era teorizado na organização mesma do trabalho do antropólogo, segundo a qual, para começar a trabalhar, era preciso definir um objeto de estudo circunscrevendo-o em uma área - isto é, se apropriar de um território (sua área) e de uma comunidade ( sua comunidade ${ }^{13}$ ). O efeito colateral de tal escolha era inevitavelmente a procura da singularidade. Da cultura em questão, era necessário descrever as especificidades singulares. O inconveniente de tal método é que, por consequência, fazia passar ao segundo plano tudo aquilo que poderia sobressair das transferências culturais, trocas e passagens.

Daí a necessidade de partir de outro postulado - de substituir a lógica que liga origem e território por uma outra lógica. É o que tenta fazer J.-L., Amselle, em seu último livro, propondo uma teoria das "ramificações culturais". Esta tem como objetivo substituir a ancoragem da identidade dentro de uma origem e um território (um terreno original) por outro princípio constitutivo de identidade cultural: o princípio segundo o qual toda cultura implica "um elemento terceiro para fundar sua própria identidade". ${ }^{14}$

\begin{abstract}
É preciso sustentar a ideia segundo a qual o recurso íntimo de uma cultura se exprime em outras culturas, dito de outra maneira, apoiar-se sobre o postulado de uma abertura ao outro de toda cultura e portanto sobre o postulado de uma interculturalidade ou uma universalidade potencial de cada uma delas. ${ }^{15}$
\end{abstract}

\footnotetext{
${ }^{13}$ N.A. Não saberíamos sublinhar mais, a este propósito, o que, de modo mais geral, a definição e apreciação das identidades culturais como todos homogêneos se devem à territorialização das ciências humanas - quer dizer, no que tange aos temas ou objetos de estudo dessas ciências em um território bem circunscrito.
}

${ }^{14}$ N.A. J.-L. Amselle, op. cit., p. 7.

${ }^{15}$ N.A. Ibid, p. 13. 
A pesquisa antropológica se encontra então orientada a uma direção radicalmente outra que é conjuntamente de uma "desapropriação" e de uma "desterritorização". Ela consiste em mostrar que toda cultura supõe uma triangulação semelhante. Ela não existe, enquanto tal, senão partindo de uma abertura original a outras culturas que, elas mesmas, não existiram de outro modo. É sua ramificação sobre uma ou outra dessas culturas (elas mesmas ramificadas) que as faz existirem. A origem se encontra, desse modo, repelida ao infinito e o território descompartimentado. Compreender a origem suporia, com efeito, que ao remontar de ramificação em ramificação, se possa encontrar um termo (uma cultura originária que não teria sido ramificada). Do mesmo modo, reterritoralizar este ou aquele fenômeno cultural implicaria que se renunciasse à procura de sua origem (ela mesma relativa) para além de suas fronteiras. Apesar disso, tal modelo não dá lugar à suposição de um difusionismo das culturas em todas as direções. À visão simplista segundo a qual tudo passaria por tudo (bem como àquela segundo a qual tudo se mistura a tudo) é preciso opor a ideia de uma série de operações singulares (jamais idênticas) constitutivas das identidades - o que não exclui nem as resistências, nem os conflitos nem as violências. Salvo quando devem ser interpretadas em outros termos. Não é porque as culturas são ameaçadas por sua mistura, sua hibridação, como por uma catástrofe, que resistências se produzem - sob a forma de tentativas vãs de reapropriação - mas porque a existência demonstrada dessas ramificações (que dá ao cosmopolitismo um fundamento imanente) constitui a realidade de nossa identidade. Tudo aquilo que se aparenta a uma redobra identitária (tudo isso que se faz à custa de tamanha violência, de um desejo de apropriação ou de reapropriação) não procede, portanto, de uma defesa de identidade, mas de sua recusa.

Essa teoria autoriza pensar a interculturalidade em termos de tradução de culturas? Uma coisa, ao menos, permite avançar nessa direção. Ela se atém à explicação mais avançada do modus operan$d i$ das ramificações. Em "Branchements"; J.-L.,Amselle explica, com efeito, que o modo privilegiado de constituição de uma cultura 
consistente na tradução de um significado particular para um significante de dimensão planetária ${ }^{16}$. Não se trata, portanto, de negar que, em tal época, tal cultura possa se apresentar como uma cultura dominante (não significando que ela sempre o foi). Ao contrário, é a existência de culturas semelhantes que permite que as outras se formem. Estas traduzem (ou convertem) para significantes dessas culturas dominantes (de vocação universal) significados particulares que se tornam assim constitutivos de uma identidade.

\begin{abstract}
A expressão de uma identidade qualquer supõe, portanto, a conversão de signos universais na sua própria língua ou, ao contrário, de significados próprios em um significante planetário, a fim de manifestar sua singularidade. A tradução e a conversão, longe de aparecerem como o resultado da confrontação de dois conjuntos linguísticos ou religiosos distintos, se caracterizam, portanto, como dados imediatos da expressão cultural. ${ }^{17}$
\end{abstract}

16 N.A. Em Branchements (op. cit. 49), J.-L. Amselle utiliza a expressão "signifiants à vocation planétaire" [significantes de vocação planetária]: "Plutôt que de disserter à l'infini sur la date de survenance de l'universalisme (Les Grecs, Saint-Paul), on voudrait se demander en quoi l'apparition et la diffusion de certains signifiants à vocation planétaire (je souligne) ont fourni une structure d'accueil à l'expression de signifiés particularistes." "Mais que dissertar ao infinito sobre a data do surgimento do universalismo (Os gregos, São Paulo), quer-se perguntar em que a aparição e difusão de certos significantes de vocação planetária (sublinho) forneceram uma estrutura de acolhimento à expressão de significados particularistas". De minha parte, preferiria substituir por "dimensão" o termo "vocação" que conota ainda muito fortemente a ideia de uma "missão universal" - tal qual ela pode ser encontrada no pensamento de Fichte ou, mais próximo de nós, em Heidegger. Lembra-me, ao contrário, que a ideia de "branchements" [ramificações] permite descrever as relações entre as culturas (então compreendidas como relações de dominação) sem subscrever à ideia de uma missão ou de uma vocação do universal encarnado. A vocação, a missão, seriam, sobretudo, a interpretação que as culturas dominantes dão ao contrário da necessidade que as demais culturas têm de se ramificar para existir.

${ }^{17}$ N.A. Jean-Loup Amselle, op. cit. p. 59. 
Nossa questão inicial era: "Pode-se pensar a relação entre as culturas segundo o modelo da tradução?" A resposta que se tentou dar nas páginas que precedem é triplamente política. Se é verdade que toda política supõe ao mesmo tempo uma memória do passado, uma crítica do presente e um pensamento do futuro, a tradução constitui o denominador comum dessas três dimensões.

1. Da memória, a ênfase na tradução das culturas (as transferências culturais) propõe uma outra abordagem. Esta se encontra orientada decididamente à lembrança do que foi traduzido e se traduziu. Ela é ao mesmo tempo liberada de sua redobra inversa sobre um patrimônio que teria esquecido ou mascarado sua heterogeneidade constitutiva.

2. No presente, ela é duplamente crítica. A consciência da interculturalidade como tradução se opõe a toda instrumentalização unilateral do passado, toda tentativa de forcluir a heterogeneidade na invocação de uma história comum. De fato, tais tentativas e instrumentalizações estão em marcha cada vez que uma identificação está em jogo. O exemplo mais recente disso é a vontade anunciada por alguns de inscrever, de maneira unívoca, a referência ao cristianismo na constituição da Europa. Mas essa consideração permite também contestar e se opor a toda política de resistência à tradução - toda vontade deliberada de dividir, até mesmo de "guetificar" as culturas, como se elas fossem entidades irredutivelmente e definitivamente separadas.

3. Enfim, fazer da tradução entre as culturas um horizonte tem um duplo efeito. Permite não subscrever, sem reservas, aos discursos identitários alarmistas de toda ordem que apenas exibem as ameaças de que tal identidade cultural seria objeto à custa de uma visão congelada e largamente fictícia desta identidade ela mesma. A identidade é sempre antes para ser inventada do que para ser defendida e a tradução constitui um 
dos motores privilegiados dessa invenção. Não são as trocas, os enxertos, as passagens que são os destruidores, mas sua ausência. Donde o segundo efeito desse pensamento. Ela autoriza a desacreditar toda política que visa a comprometer, de uma maneira ou de outra, a mobilidade das "identidades culturais" - abertura aos outros que, de encontro a toda retórica nacionalista, não constitui jamais uma ameaça, mas a promessa inscrita no coração mesmo da ideia da cultura.

Recebido em: 06/11/2015

Aceito em: 18/12/2015

Publicado em maio de 2016 


\title{
LA TRADUCTION ENTRE LES CULTURES ${ }^{18}$
}

\author{
Marc Crépon* \\ École Normale Superiéure em Paris
}

La question que je poserai est la suivante : Peut-on penser la relation entre les cultures selon le modèle d'une traduction ? Est-il légitime d'étendre ce que nous pouvons expérimenter de la relation entre les langues (ce qui se passe entre elles et en chacune d'elles dans la traduction) à l'interculturalité ? En réalité, il s'agit de deux questions, car cette extension peut être pensée de deux façons.

\section{La traduction, comme horizon cosmopolite}

La première est programmatique et téléologique. Elle consiste à dire que les cultures sont vouées à se traduire les unes dans les autres, qu'elles n'ont pas d'autre devenir que cette relation commune qui enrichit chacune de ce qu'elle reçoit des autres - des multiples passages, échanges, transferts qui donnent à chacune son identité, en même temps qu'ils avèrent leur caractère commun. La traduction entre les cultures, alors, n'est pas perçue comme un phénomène ponctuel et épisodique (quelque chose qui arriverait parfois à l'une ou l'autre d'entre elles). Elle est ce qui va venir et

\footnotetext{
${ }^{18}$ Artigo originalmente intitulado « La traduction entre les cultures » publicado na Revue Germanique Internationale, vol.21, 2004, p.71-82.

* Doutor em Filosofia e tradutor, Diretor de Pesquisa no CNRS (Centre Nationale de Recherche Scientifique), chefe do departamento de Filosofia da École Normale Superiéure em Paris.
} 
ce qui doit venir - le dépassement promis et progressif de leur cloisonnement ou de leur repli sur elles-mêmes. Penser la relation entre les cultures comme traduction, c'est annoncer qu'il sera impossible désormais de parler des différentes cultures comme d'entités homogènes, développées à partir d'un fond propre, car, par le biais de la traduction, elles ne pourront rester identiques à ellesmêmes. Elles seront progressivement, chacune de façon singulière, un miroir de toutes les autres. Prise dans une telle perspective, l'extension du concept de traduction consiste à penser la relation entre les cultures dans un horizon cosmopolite. L'interculturalité y dessine les contours d'une nouvelle utopie - celle d'un monde dans lequel les frontières culturelles, les barrières que les cultures dressent entre les individus seront abolies.

De cette dimension téléologique, voire même prophétique, de cette espérance cosmopolite, quelques-unes des théories majeures de la traduction linguistique offrent le modèle - à commencer par celle que Benjamin propose dans La Tâche du traducteur ${ }^{19}$. Que dit-il de la traduction qui puisse éclairer cet horizon ? Qu'elle est, dans le temps de son effectuation, le signe qui renvoie la pluralité des langues à un langage pur, commun à toutes. A l'oeuvre littéraire, il reconnaît le statut singulier de valoir comme un appel en direction de ce langage. L'oeuvre littéraire, en tant que telle, réclame son décloisonnement dans une langue donnée. Parce qu'elle ne se réduit pas à sa communication, elle est tendue vers un autre horizon : celui de l'harmonie des langues. Traduire, pour Benjamin, c'est éprouver jusqu'à quel point les langues entretiennent entre elles un rapport intime - c'est expérimenter le fait qu'elles sont apparentées. La traduction les fait converger à l'infini.

\footnotetext{
${ }^{19}$ Mais on pourrait encore y ajouter les réflexions de Rosenzweig sur la traduction et notamment sa traduction de la Bible en allemand, avec Buber (cf. " Traduction et rédemption, la question du nationalisme dans 1 ' oeuvre de Rosenzweig ", in Ma r c Crépon, Le Malin génie des langues, Paris, Vrin, 2000, p. 141-155), ou, plus près de nous, le travail de Jacques Derrida sur cette question.
} 
D’un tel postulat, présenté ici de façon sommaire ${ }^{20}$, plusieurs choses peuvent être retenues. D'abord que la traduction est porteuse d'une promesse qu'on pourrait presque dire eschatologique. Elle renvoie aux « fins de l'humanité ». Au-delà de l'apparentement qu'elle fait pressentir, elle se présente comme un travail, une oeuvre qui conduit les hommes dans une certaine direction. Traduire, mais aussi être confronté à des traductions (lire des traductions), c'est avoir une expérience de sa langue qui rend impossible son repli sur une culture déterminée, c'est désolidariser l'expérience et la pratique de la langue - mais aussi le plaisir pris à la (aux) langue(s) - de tout sentiment d'appartenance. Ce qui vient à la langue, ce qui me vient dans la langue m' arrive d'ailleurs. Autant dire que la traduction opère une véritable désappropriation de ma (notre) langue - elle la déporte vers une communauté qui n'est plus seulement celle de ses colocuteurs. Elle me rapproche de ceux qui parlent d'autres langues (les langues traduites), de même que ce qui se traduit de leur langue dans $m a$ langue les rapproche de moi et fait que cette langue n'est plus tout à fait, ou du moins plus exclusivement la mienne. Ce qui se brouille, avec la traduction, c'est la carte du mien et du leur. C'est aussi tout rêve d'une appropriation (d'une maîtrise et d'une possession de as langue, comme « langue maternelle »). Je ne puis être maître de ma langue, je ne puis jamais la posséder, dès lors que je ne suis pas maître de ce qui, par le biais de la traduction, risque, à chaque instant, de lui arriver.

Mais aussi, la théorie benjaminienne de la traduction nous apprend qu'aucune langue n'est autosuffisante. Elle nous dit même que cela n'ajamais été le cas. Elle renvoie à un « toujours », le « toujours » de la traduction, dont le premier effet est de rendre caduc tout recours à une hypothétique origine. Toujours les langues ont vécu de la traduction et par la traduction. Celle-ci ne leur est pas venue a posteriori - une fois qu'elles étaient déjà constituées (comme une catastrophe ou comme un enrichissement). Elle est

${ }^{20}$ Cf. « La magie du langage, Benjamin et les surréalistes », in Marc Crépon, Les Promesses du langage, Paris, Vrin, 2001, p . 101-131. 
bien davantage la loi de leur devenir. Ce qui fait la grandeur d'une langue (à supposer qu'une telle expression ait encore un sens), ce n'est pas son antiquité ni son origine, ce n'est pas qu'elle soit apparentée telle ou telle langue qui ferait l'objet d'une valorisation ellemême problématique (le grec, le latin, le sanscrit), c'est qu'elle est restée (et reste encore) disponible pour la traduction - c'est que, grâce à elle, il y a, dans les deux sens, de la traduction. Toute langue est donc tributaire de ce qui se traduit en elle et à partir d'elle, dans les autres, car c'est alors seulement qu'elle fait signe vers ce langage pur encore inaccessible (et tout à fait hypothétique) qui n'est rien d'autre qu'une langue pleinement désappropriée, une langue qui, parce qu'elle ne serait la propriété de personne, pourrait être commune à tous - une langue promise.

Ce modèle prophétique a- t-il un sens lorsqu'on ne parle plus de traduction entre les langues, mais de traduction entre les cultures. Cela supposerait qu'on fasse de cette traduction une, sinon la « fin de l'homme ». L'horizon cosmopolite de la diversité des cultures, ce serait leur traduction respective les unes dans les autres. Mais, aussitôt, plusieurs questions se posent, qui sont de deux ordres. 1 / Pour peu qu'on suive les réflexions de Benjamin, qu'on cherche à les transposer de la diversité des langues à celle des cultures, on est confronté à la difficulté suivante : quelle harmonie et quelle unité se trouvent avérées dans cette traduction ? Quel est le sens de cette tâche infinie et inachevable que serait la traduction des cultures, quelle promesse s'y trouve investie ? Quel est l'équivalent de ce «langage pur » que postule Benjamin ? Sommes-nous, une fois de plus, reconduits au postulat de l'unité et de l'identité de la nature humaine ? Si tel est le cas, il ne pourrait plus s'agir d'une idée transcendante, mais seulement d'une unité immanente : l'unité d'un faire. Par la «traduction des cultures », l'humanité se ferait. Et ce qui se ferait par là ne pourrait être en aucun cas la réduction des différences. Au contraire, il n'y aurait d'unité que par et dans la diversité des modes de traduction. Toutes les cultures n'ont pas eu (et n'ont toujours pas) la même façon de traduire et de se traduire. Elles n'ont pas été en contact de la même façon. On 
ne peut nier qu'à toute époque de l'histoire, il y a eu des « cultures dominantes » ou « rayonnantes » (sans que cette domination ou ce rayonnement implique ici un quelconque surcroît de valeur ou une hypothétique supériorité spirituelle) et des "cultures dominées ». Il y a eu des cultures qui, pour des raisons historiques, se prêtaient davantage à être «traduites » - qui se trouvaient même dans la position d'imposer à d'autres la nécessitée ${ }^{11}$ de les « traduire ». D'autres, au contraire, auxquelles il était difficilement reconnu (voir pas du tout) qu'elles aient quoi que ce soit à traduire (et qui néanmoins se traduisaient). Et pourtant, dans cette pluralité des modes de traduction de la diversité, il reste un dénominateur commun : la traduction elle-même. Pour le dire autrement, l'unité qui se trouverait avérée dans la traduction et par la traduction ne serait rien d'autre que le traduire lui-même. Il y aurait en quelque sorte un « çà se traduit » ou «ça traduit » commun à toutes les cultures. Ou encore un «dans toute culture, il y a de la traduction».

2 / Le deuxième ordre de questions nous reconduit à notre interrogation initiale et soumet le premier à ses conditions. Celle-ci était : Est-il légitime de parler de traduction entre les cultures ? Peut-on appliquer sans réserve le concept de traduction à un passage, à une relation autres que ceux qui arrivent aux langues et entre les langues. Traditionnellement, on parle plutôt d'emprunts, d'importations et/ou d'exportations de « contenus culturels ». On relève la façon dont des moeurs, des pratiques culinaires et vestimentaires, des traditions passent d'une " aire culturelle » à une autre, deviennent partie intégrante (non sans résistances parfois) de 1' "aire culturelle » qui les reçoit. On pense enfin, au titre du métissage, le mélange ou la coexistence de ces contenus qu'on dit d'origines différentes (des religions, des façons de se vêtir, des façons de se nourrir, des rites, etc.). D'une telle façon de voir, il faut aussitôt souligner les limites. Elle préserve le dogme de cultures homogènes originelles (identiques à elles-mêmes) qui doivent apprendre

${ }^{21}$ Voir, plus loin, comment la théorie anthropologique des « branchements » (J.-L. Amselle) permet d'éclairer cette nécessité. 
à coexister ou qui se mêlent les unes aux autres, dans un second temps seulement.

C'est ce second temps qui fait problème. Et c'est pour résoudre ce problème que le concept de traduction doit être affiné. Ce concept, en effet, suppose d'abord davantage qu'un transfert ou qu'une simple importation. Il n'y a pas de traduction sans transformation. Traduire, c'est passer d'un signifiant à un autre - en préservant, autant que faire ce peu, mais jamais totalement, le signifié. Si la traduction entre les cultures devait s'avérer le modèle le plus pertinent pour penser l' interculturalité, elle supposerait un passage de cet ordre. Elle impliquerait qu'il existe des signifiés culturels qui, d'une culture à l'autre, changent de signifiant - ou encore des signifiés dont le passage exige l'invention d'un autre signifiant (une invention qui deviendrait alors le moteur privilégié du devenir des cultures). L'idée d'assigner à la traduction entre les cultures une dimension eschatologique comparable à celle que Benjamin assignait à la traduction entre les langues exige donc qu'on ait préalablement répondu à la question : Est-ce de cette façon (au prix d'un tel changement de signifiant) que les cultures se traduisent et même qu'elles se sont toujours traduites ?

Mais le concept de traduction doit suggérer encore davantage, si l'on veut en finir avec cette idée d'un second temps - c'est-à-dire sortir du préjugé durable, selon lequel ce qui se passerait entre les cultures (ce qui leur arriverait) viendrait toujours après coup, en un second temps. Tant que ce préjugé perdure, en effet, l'histoire des cultures reconduit à une antériorité de l'identité sur ce qui lui arrive et donc aux mythes conjoints de l'origine et de l'homogénéité. Dans un texte célèbre, Jakobson distingue trois sortes de traduction :

La traduction intralinguale ou reformulation (rewording) consiste en l'interprétation des signes linguistiques au moyen d'autres signes de la même langue. La traduction interlinguale ou traduction proprement dite consiste en l'interprétation de signes linguistiques au moyen d'une autre langue. La traduction intersémiotique ou transmutation 
consiste en l'interprétation des signes linguistiques au moyen de systèmes de signes non linguistiques ${ }^{22}$.

Si l'on s'en tient à une telle classification pour penser l' interculturalité, le dogme du second temps est maintenu intact. On aurait trois types de traduction interculturelles. Celle qui transcrit dans le même système de signes un phénomène culturel (par exemple, les différentes versions d'une même histoire au cinéma), celle qui transcrit ce phénomène d'une culture dans une autre (comme l'adaptation américaine d'un film européen), celle enfin qui traduit un phénomène culturel donné dans un autre système de signes, (l'adaptation cinématographique d'un roman, voire d'une chanson ou d'un ensemble de chansons ${ }^{23}$ ). Dans tous ces cas de figure, la traduction est toujours seconde par rapport à une identité première. C'est donc un quatrième modèle de traduction intralinguistique qu'il faut impliquer : une traduction - d'avant la traduction, une traduction qu'on pourrait presque dire originaire, si l'on voulait déplacer (pervertir peut-être) la notion d'origine. Il s'agirait alors de penser l'identité culturelle sur le modèle d'une identité linguistique qui ne se constituerait que par et dans la traduction.

Ce faisant, il est nécessaire de revenir encore une fois de la dimension de l'avenir à celle du passé - de montrer qu'effectivement toute culture est, dans son identité, de façon constitutive, le résultat d'une traduction, qu'elle n'est pas l'exploitation ou le développement d'un fond propre qui aurait le statut d'un archi-patrimoine. Pour élucider, comme on a tenté de le faire, la question de l'harmonie (en la réduisant au fait brut de la traduction, comme dénominateur commun), il faut donc passer de la dimension téléologique et même utopique de cette pensée des relations interculturelles à sa dimension critique.

${ }_{22}$ Jakobson, Essais de linguistique générale, t. I, Paris, Éd. de Minuit, 1963, p . 79.

${ }^{23}$ Voir, par exemple, le film d'Alain Resnais On connaît la chanson, qui donne dans le même temps des chansons populaires et leur traduction dans le récit qui les entrelace. 


\section{La traduction, dans l'horizon de la critique}

Au commencement de cette réflexion, supposition était faite qu'il y avait deux façons de penser l'interculturalité, sur le mode d'une traduction. La promesse eschatologique était la première. La critique est la seconde. Elles ne sont évidemment pas complètement dissociables l'une de l'autre.Leur articulation correspond même à ce qui a toujours fait l'essence même de l'utopie - à savoir la conjonction d'un discours critique et d'un programme qui était toujours davantage qu'un programme et même qu'une prophétie : une promesse. On se souvient, en effet, que la plupart des descriptions prophétiques d'une cité utopique, à commencer par l'Utopia de Thomas More, s'ouvraient sur une critique de la cité existante, sur le relevé de tous les maux qui l'accablaient, avant d'envisager un programme de réformes qui promettait leur solution dans un avenir indéterminé.

En quoi consiste ici la critique ? Quel est le relevé des maux ? On pourrait se contenter d' énumérer les atrocités (les malheurs et les misères) qui peuvent être mises au compte d'une conception homogénéisante des cultures - raconter les conflits qui, hier et aujourd'hui encore, ont eu et ont toujours pour raison une conception de l'identité culturelle qui est aussi un déni de traduction. Cela reviendrait à dire que si l'on s'était habitué à penser la relation entre les cultures en termes de traduction plutôt qu'en termes de concurrence - si l'on avait compris que la traduction n'est pas un épisode aléatoire de leur devenir, mais la condition même de leur vie et de leur "identité », on aurait évité ces fantasmes de l'altération et de la disparition (de l'empiétement et de la confusion) qui ont donné aux conflits identitaires un tour si meurtrier. Mais ce n'est sans doute pas suffisant.

La critique doit porter au-delà. Il lui faut déconstruire la notion même d'identité culturelle (avec, notamment, tout ce qu'elle peut comporter de fantasmes de l'origine, de l'unité, de l'intégrité ou de la pureté, etc.)déconstruire donc cette façon de comprendre, d'analyser et de décrire les identités culturelles comme des identités homogènes, unes et identiques à elles-mêmes, cette façon aussi de 
raconter leur histoire, celle de leur origine, de leur formation et de leur développement sous le schème d'une unité. Avec la critique, la question se trouve donc déplacée. Elle ne concerne plus l'avenir des cultures, en tant qu'elles seraient destinées à se traduire les unes dans les autres - l' interculturalité comme horizon cosmopolite. Elle s'intéresse à l'histoire inachevée de leur formation. Elle a pour objet de mettre en évidence la traduction elle-même comme constitution originaire de toute culture. Elle vise à montrer qu'à raconter l'histoire constitutive des cultures, sans céder au fantasme d'une origine unidentitaire, on trouve toujours, au commencement, de la traduction. La traduction ne vient pas après coup, comme le suppose toute théorie du métissage. Elle est toujours déjà là.

Mais comment peut-on montrer que, à l' encontre de toute une tradition de réflexion sur les identités culturelles ${ }^{24}$, les cultures ne sont pas des entités cloisonnées, opposées et exposées les unes aux autres, auxquelles l'épreuve de l' altérité serait arrivée un jour comme la menace d'une catastrophe (comme un malheur ou une violence faite à leur intégrité) ? Com-ment peut-on montrer qu'elles se sont, depuis le commencement, traduites les unes dans les autres - que l'événement de la traduction donc leur est consubstantiel ? Contre le fantasme de cultures homogènes - qu'il faudrait protéger ou promouvoir - , l'idée d'une constitution originellement hétérogène des cultures ne doit pas rester une hypothèse théorique et s'exposer au reproche d'être une vue de l'esprit.

D'où la nécessité d'interroger le travail des anthropologues. C'est à l'anthropologie actuelle qu'il faut demander s'il est vrai que (au vu d'enquêtes, dont la méthode et les orientations demandent à être précisées ${ }^{25}$ et interrogées) l'identité de chaque culture dépend de la façon qu'a eue chacune, pour des raisons nécessairement diverses - des raisons, en tout cas, qui ne renvoient en aucun cas à la qualité singulière d'un esprit ou d'un caractère — de traduire ou

24 Tradition qu' on retrouve encore dans les théories contemporaines du multiculturalisme, comme celles de Charles Taylor et de Will Kymlicka.

${ }^{25} \mathrm{La}$ question du terrain de 1 ' anthropologue s'avère ici décisive. 
de ne pas traduire ; s'il est vrai que ces identités sont fonction de l'étendue de ce qu'elles offrent et ont offert à la traduction, de ce qu'elles ont accepté ou refusé, connu ou méconnu.

Se tourner vers l'anthropologie, c'est aussi, dans un registre plus politique (dont il ne peut être fait abstraction ici), une façon inédite de répondre aux revendications identitaires, à un double titre. Peu de disciplines, d'abord, auront éprouvé à ce point la nécessité de faire un retour sur elles-mêmes - d'interroger leur participation à l'une des catastrophes majeures des deux derniers siècles (l'impérialisme colonial) et de remettre en question, dans cette perspective, la pertinence de leurs représentations et l'usage de leurs concepts - à commencer par celui d ' " identité culturelle». Des anthropologues, on peut attendre donc qu'ils aient déjà effectué une partie du travail pour leur propre compte, qu'ils se soient déjà interrogés, par exemple, sur le lien qui a pu exister entre l'imposition du cadastre à une colonie, la circonscription administrative d'un territoire, l'identification d'un peuple et la définition d'un caractère. Ils savent d'autant plus que les cultures ne sont pas homogènes, qu'elles ne procèdent pas de l'exploitation infinie d'un fond propre (lié à un terrain déterminé ou à quelque autre forme de propriété) que, pendant longtemps, c'est à l'un ou l'autre de ces paradigmes qu'ils les ont rapportées.

Mais surtout, le recours à l'anthropologie s'avère indispensable, s'il est vrai que les limites ne sont pas imperméables entre les définitions ou les descriptions identitaires d'une culture donnée et les discours qui revendiquent cette identité et sa reconnaissance, qui déclinent une théorie du propre et de la propriété en même temps qu'ils formulent le réquisit d'une appropriation et déplorent une perte d'identité ou avertissent d'une menace d'expropriation. A l'encontre de ces discours politiques, elle seule est en mesure d'apporter la preuve empirique que la culture ne s'identifie pas à un faisceau de propriétés, à un ensemble de choses qui nous appartiendraient (la langue, les moeurs), qui ne seraient jamais suffisamment appropriées et que l'on devrait craindre de perdre - la langue qui ne serait plus appropriée (impure, contaminée par des mots étran- 
gers, etc.), les traditions dont la perte dépouillerait « les détenteurs », « les représentants » ou « les ayants droit de la communauté » (qui sont-ils au juste ? Quelle hypothétique communauté forment-ils ?), ceux qui parlent et agissent au nom de la culture (au nom de ce qu'ils croient détenir en propre : ces traditions, précisément).

Penser 1' interculturalité comme traduction consiste donc à se donner les moyens de ne laisser intacte aucune de ces appropriations - à montrer que ce que chaque culture s'imagine avoir en propre (ce dont elle fait un trait caractéristique essentiel) est certainement l'effet d'une traduction, voire d'une succession de traductions - de telle façon qu'il serait presque impossible de démêler l'originel du traduit. Il s'agit de battre en brèche tout discours qui persévérerait dans la quête d'un contenu culturel authentique (quelque chose qui appartiendrait en propre à une culture et à cette culture seulement ${ }^{26}$ ). C'est seulement au prix d'une telle désappropriation

${ }^{26}$ Je me demandais, en écrivant ces lignes, comment leur donner un tour moins abstrait, quelle illustration proposer qui ne soit pas encore une fois la déconstruction d 'un discours philosophique déterminé sur la ou les culture(s), quand mes enfants sont rentrés de l'école. Ils avaient participé, dans leur école primaire , à " la semaine du goût » et on leur avait fait tester diverses épices, leur demandants'ils connaissaient des plats dans lesquels on les retrouvait. L e u r récit $\mathrm{m}$ 'a suggéré quelques réflexions. D 'abord, on pourrait dire $q u$ e cette semaine $d$ u goût qui ne privilégie pas 1 'apport diététique et nutritif des aliments, mais leur goût - n'est pas étrangère à une certaine représentation de « la culture française », à l'idée, en tout cas, que cette culture comporte comme 1 ' un de ces éléments constitutifs un certain savoir-faire culinaire qui appelle en retour une " éducation du goût ». Ensuite, cette semaine se justifie d 'une déploration comparable à celles q u ' o n analysait un peu plus haut. Le goût se perd, les enfants ne savent plus reconnaître les saveurs. Encore un peu, ils ne seront plus à même d 'apprécier comme il se doit cette cuisine qui fait pourtant partie de leur culture, ils s'en trouveront en quelque sorte dépossédés, au profit d ' une alimentation standardisée. Mais à ces deux remarques, il fallait aussitôt en ajouter une troisième. Qu ' ava ient- ils appris à reconnaître, ces enfants dont le goût devait être éduqué ? Des fruits, au nombre desquels figuraient des ananas. Des épices qui, il y a quelques siècles, étaient totalement inconnus en Europe. Des fruits, des épices qui désormais rentrent dans la composition de nombreux plats qu 'on identifie à la « cuisine française ». J e me suis dit alors qu ' il y avait là une histoire (qui a certainement déjà été écrite) qui impliquait toute une série de passages: le voyage des épices, 
que l'interculturalité peut être légitimement pensée comme traduction et dégager un horizon cosmopolite.

Que dit aujourd'hui l'anthropologie non seulement des cultures actuelles, mais aussi de leur passé ${ }^{27}$ (puisqu'il nous faut revenir encore et toujours sur cette histoire qui aura été si souvent mythique) - que dit-elle qui puisse nous permettre de penser la relation qu'elles entretiennent les unes avec les autres sur le modèle d'une traduction constitutive ? Si l'on en croit les travaux de JeanLoup Amselle, la discipline est exposée à deux écueils. Le premier est de souscrire à la thèse selon laquelle, effectivement, il n'y aurait plus aujourd'hui de cultures homogènes - mais seulement un monde homogène. Ou plutôt, les cultures pèseraient peu de poids devant la globalisation et l'homogénéisation d'un monde qui aurait déjà décidé devleur sort - les vouant sinon à une disparition certaine, du moins à une «folklorisation » de plus en plus exotique. Des cultures, il ne resterait, à terme, que leur folklore. Le second consiste à croire que ce nouvel état de fait vient mettre un terme à un passé dans lequel les cultures étaient nettement différenciées et cloisonnées. Pour le dire en d'autres termes, il y aurait eu un temps

leurs premiers accommodements, leur association avec d 'autres produits, des viandes, des légumes, des poissons qui ne se cuisinaient peut-être pas là où elles poussaient. Tout cela pour dire que, à la réflexion, « la cuisine française », fleuron de « la culture », était finalement une affaire assez compliquée qui avait nécessité beaucoup de médiations, beaucoup d ' appropriations non seulement de produits, mais aussi de savoir-faire qui s'étaient développés ailleurs. Et q u ' e n faisant l'histoire de ces appropriations- traduct ions successives, elle se révélait tributaire d ' autres cultures (aux deux sens du terme), d ' autres traditions culinaires, de sorte que , finalement, il devenait assez difficile de faire de cette cuisine " le propre » $d$ ' une culture déterminée, encore moins l'expression d ' un génie culinaire propre à un terroir ou à une série de terroirs.

${ }^{27}$ Dans Au coeur de l'ethnie (Paris, L a Découverte, 1985), Jean- Loup Amselle rappelle combiena été grande l'hostilité que, pendant longtemps, 1 ' anthropologie a manifesté à 1 'encontre de toute approche historique ou historiciste des cultures. Cette approche historique est pourtant nécessaire, si l'on veut procéder à la déconstruction du mythe d'identités culturelles homogènes et identiques à elles-mêmes. La tâche de l'histoire, dans l'anthropologie, est de casser le moule de l'homogénéité et de l'identité, en mettant l'hétérogénéité au coeur de l'origine. 
où l'appropriation était naturelle et immédiate (chacun avait une culture, la culture propre à sa communauté - une culture distincte de toutes les autres qui l'incluait dans cette communauté et suffisait à le différencier de tous ceux qui n'en faisaient pas partie) et un temps où elles auraient commencé de se mêler les unes aux autres, au risque d'une confusion accrue, voire à se heurter (pour résister à ce mélange). Choc des cultures ou " créolisation $»^{28}$ du monde, pour reprendre les termes d'Edouard Glissant, dans les deux cas se trouve postulée l'existence originelle de cultures différenciées. L'un et l'autre sont dominés par le renvoi à une appropriation originelle.

Si l'anthropologie est particulièrement bien placée pour mesurer ces risques, c'est que longtemps, elle fut dominée par un tel postulat. Celui-ci (qui suppose, à l'origine, des sociétés closes) s'imposait avec d'autant plus d'évidence qu'il était théorisé dans l'organisation même du travail de l'anthropologue, selon laquelle, pour commencer à travailler, il fallait définir un sujet d'étude en circonscrivant un terrain - c'est-à-dire s'approprier un territoire [son terrain) et une communauté ( $s a$ communauté ${ }^{29}$ ). La rançon d'un tel choix était inévitablement la recherche de la singularité. De la culture en question, il était nécessaire de décrire les spécificités singulières.L'inconvénient d'une telle démarche est que, du

${ }^{28}$ Voir la critique que fait J . - L . Amselle de la théorie d 'une «créolisation du monde ", dans son dernier livre Branchements, anthropologie de l'universalité des cultures, Paris, Flammarion, 2001, p. 17 sq. : « L ' idée de créolisation correspond à une conception polygéniste du peuplement humain, dans laquelle les différentes espèces feraient l'objet $d$ ' un travail permanent de croisement et $\mathrm{d}$ ' hybridation. Ce boutage culturel du monde représente ainsi 1 'avatar ultime de la pensée biologico-culturelle, telle qu'elle s'est pleinement développée dans 1 ' anthropologie culturelle américaine. C'est en partant du postulat de l'existence d'entités culturelles discrètes nommées « cultures » que l'on aboutit à une conception d'un monde postcolonial ou postérieur à la guerre froide vu comme être hybrides » [op. cit., p. 21-22).

${ }^{29}$ On ne saurait trop souligner, à ce titre, ce que, de façon plus générale, la définition et 1 ' appréhension des identités culturelles comme des tous homogènes doivent à la territorialisation des sciences de 1 'homme- c'est-à-dire au rapport des thèmes ou des sujets d ' étude de ces sciences à un territoire bien circonscrit. 
même coup, elle faisait passer au second plan tout ce qui pouvait relever des transferts culturels, des échanges et des passages.

D'où la nécessité de partir d'un autre postulat - de substituer à la logique qui lie origine et territoire une autre logique. C'est ce que tente de faire J.-L. Amselle, dans son dernier livre, en proposant une théorie des «branchements culturels ». Celle-ci a pour but de substituer à l'ancrage de l'identité dans une origine et un territoire (un terroir originel) un autre principe constitutif de l'identité culturelle : le principe, selon lequel toute culture implique « un élément tiers pour fonder sa propre identité $»^{30}$ :

Il faut soutenir l'idée selon laquelle le ressort intime d'une culture s'exprime dans les autres cultures, autrement dit, s'appuyer sur le postulat d'ouverture à l'autre de toute culture et donc sur celui d'une interculturalité ou d'une universalité potentielle de chacune d'elles. ${ }^{31}$

L'enquête anthropologique se trouve alors orientée dans une tout autre direction qui est conjointement celle d'une " désappropriation » et d'une "déterritorialisation ». Elle consiste à montrer que toute culture suppose une semblable triangulation. Elle n'existe, en tant que telle, qu'à partir d'une ouverture originelle à d'autres cultures qui, elles-mêmes, n'ont pas existé autrement. C'est leur branchement sur l'une ou l'autre de ces cultures (ellesmêmes branchées) qui les fait exister. L'origine se trouve ainsi repoussée à l'infini et le territoire décloisonné. Comprendre l'origine, cela supposerait, en effet, que remontant de branchement en branchement, on puisse trouver un terme (une culture originaire qui n'aurait pas été branchée). De même, re-territorialiser tel ou tel phénomène culturel impliquerait qu'on renonce à chercher son origine (elle-même relative) au-delà des frontières. Pour autant, un

30 . J- L . Amselle, op. cit., p. 7.

31 Ibid., p. 13. 
tel modèle ne donne pas lieu à la supposition d'un diffusionnisme des cultures tous azimuts. À la vision simpliste selon laquelle tout passerait dans tout (comme à celle selon laquelle tout se mêlerait à tout), il faut opposer l'idée d'une série d'opérations singulières (jamais identiques) constitutives des identités - ce qui n'exclut ni les résistances ni les conflits ni les violences. Sauf qu'alors ceux-ci doivent être interprétés en de tout autres termes. Ce n'est pas parce que les cultures sont menacées par leur mélange, leur hybridation, comme par une catastrophe, que des résistances se produisent sous la forme de tentatives vaines de réappropriations - , mais parce que l'existence avérée de ces branchements (qui donne au cosmopolitisme un fondement immanent) constitue la réalité de notre identité. Tout ce qui s'apparente à un repli identitaire (tout ce qui relève, au prix de combien de violences, d'un désir d'appropriation ou de réappropriation) ne procède donc pas d'une défense de l'identité, mais de son refus.

Cette théorie autorise- t-elle à penser l'interculturalité en termes de traduction des cultures ? Une chose, au moins, permet d'avancer dans cette direction. Elle tient à l'explication plus avancée du mode opératoire des branchements. Dans Branchements, J.-L. Amselle explique, en effet, que le mode privilégié de constitution d'une culture consiste dans la traduction d'un signifié particulier dans un signifiant à dimension planétaire ${ }^{32}$. Il ne s'agit donc pas

32 Dans Branchements \{op. cit., p . 49), J . - L . Amselle utilise l'expression de « signifiants à vocation planétaire» : «Plutôt que de disserter à l'infini sur la date de survenance de l'universalisme (Les Grecs, Saint-Paul), on voudrait se demander en quoi 1 'apparition et la diffusion de certains signifiants à vocation planétaire (je souligne) ont fourni une structure d'accueil à l'expression de signifiés particularistes.» Je préférerai, pour ma part, substituer le terme de « dimension» à celui de «vocat ion» qui connote encore trop fortement l'idée d ' $\mathrm{u}$ n e « mission universelle » - telle qu'ell e a pu se rencontrer dans la pensée de Fichte ou, plus près de nous, de Heidegger. Il $\mathrm{m}$ e semble, au cont raire, que l'idée de «branchements» permet de décrire les relations entre les cultures (y compris des relations de domination) sans souscrire à l'idée d'une mission ou d'une vocation de l'universel incarné. La vocation, la mission, ce serait, bien davantage, 1 ' interprétation que les cultures dominantes donnent à rebours de la nécessité où sont les autres de se brancher pour exister. 
de nier qu'à telle époque, telle culture puisse se présenter comme une culture dominante (ce qui ne signifie pas qu'elle l'a toujours été). Au contraire, c'est l'existence de semblables cultures qui permet aux autres de se former. Celles-ci traduisent (ou convertissent) dans les signifiants de ces cultures dominantes (à vocation universelle) des signifiés particuliers qui deviennent ainsi constitutifs d'une identité :

L'expression d'une identité quelconque suppose donc la conversion de signes universels dans sa propre langue ou, à l'inverse, de signifiés propres dans un signifiant planétaire afin d'y manifester sa singularité. La traduction et la conversion, loin d'apparaître comme le résultat de la confrontation de deux ensembles linguistiques ou religieux distincts, se caractérisent donc comme des données immédiates de l'expression culturelle. ${ }^{33}$

Notre question initiale était : «Peut-on penser la relation entre les cultures selon le modèle de la traduction ? » La réponse qu'on a essayé de donner dans les pages qui précèdent est triplement politique. S'il est vrai que toute politique suppose à la fois une mémoire du passé, une critique du présent et une pensée de l'avenir, la traduction constitue le dénominateur commun de ces trois dimensions. 1 / De la mémoire, l'accent mis sur la traduction des cultures (les transferts culturels) propose une autre approche. Celle-ci se trouve orientée résolument vers le rappel de ce qui a été et s'est traduit. Elle est du même coup affranchie de son repli inverse sur un patrimoine qui aurait oublié ou masqué son hétérogénéité constitutive. 2 / Dans le présent, elle est doublement critique. La prise en compte de l'interculturalité comme traduction s'oppose à toute instrumentalisation unilatérale du passé, toute tentative de forclore l'hétérogénéité dans l'invocation d'une histoire commune. De fait,

${ }^{33}$ Jean- Loup Amselle, op. cit., p . 59. 
de telles tentatives et instru-mentalisations sont à l'oeuvre chaque fois qu'une identification est en jeu. L'exemple le plus récent en est la volonté affichée par certains d'inscrire, de façon univoque, la référence au christianisme dans la constitution de l'Europe. Mais cette prise en compte permet aussi de contester et de s'opposer à toute politique de résistance à la traduction - toute volonté délibérée de cloisonner, voire de " ghettoiser » les cultures, comme si elles étaient des entités irréductiblement et définitivement séparées. 3 / Enfin, faire de la traduction entre les cultures un horizon a un double effet. Cela permet de ne pas souscrire, sans réserve, aux discours identitaires alarmistes de tous ordres qui n'exhibent les menaces dont telle identité culturelle ferait l'objet qu'au prix d'une vision figée et largement fictive de cette identité elle-même. L'identité est toujours davantage à inventer qu'à défendre et la traduction constitue l'un des moteurs privilégiés de cette invention. Ce ne sont pas les échanges, les greffes, les passages qui sont destructeurs, mais leur absence. D'où le second effet de cette pensée. Elle autorise à discréditer toute politique qui vise à compromettre, d'une façon ou d'une autre, la mouvance des « identités culturelles » - cette ouverture aux autres qui, à l' encontre de tout argumentaire nationaliste, ne constitue jamais une menace, mais la promesse inscrite au coeur même de l'idée de culture.

Recebido em: 06/11/2015

Aceito em: 18/12/2015

Publicado em maio de 2016 